\title{
Associations between dairy-product consumption and body composition: results from the Caerphilly study
}

\author{
A. Dougkas ${ }^{1}$, A. M. Minihane ${ }^{1}$, C. K. Reynolds ${ }^{2}$, P. C. Elwood ${ }^{3}$ and D. I. Givens ${ }^{2}$ \\ ${ }^{1}$ Hugh Sinclair Human Nutrition Group, School of Chemistry, Food Biosciences and Pharmacy, Faculty of Life Sciences \\ University of Reading, Reading RG6 6AP, UK, ${ }^{2}$ Nutritional Sciences Research Unit, School of Agriculture, Policy and \\ Development, Faculty of Life Sciences University of Reading, Reading RG6 6AR, UK and ${ }^{3}$ Department of Epidemiology, \\ Statistics and Public Health, Cardiff University, University Hospital of Wales, Heath Park, Cardiff CF14 4XN, UK
}

There is evidence of a moderate negative association between dairy consumption and body weight ${ }^{(1)}$. However, there is a paucity of evidence that considers the effect of different types of dairy products on adiposity. The aim of the present epidemiological analysis was to cross-sectionally examine the relationship between milk, cheese, cream and butter consumption and body weight and estimates of adiposity (waist circumference, waist: hip ratio and skinfold thicknesses).The analysis is based on data from the Caerphilly study, a cohort of 2512 men, aged 45-59 years at recruitment (phase I), which was followed for 10 years with 5-year intervals (phases II and III) ${ }^{(2)}$.

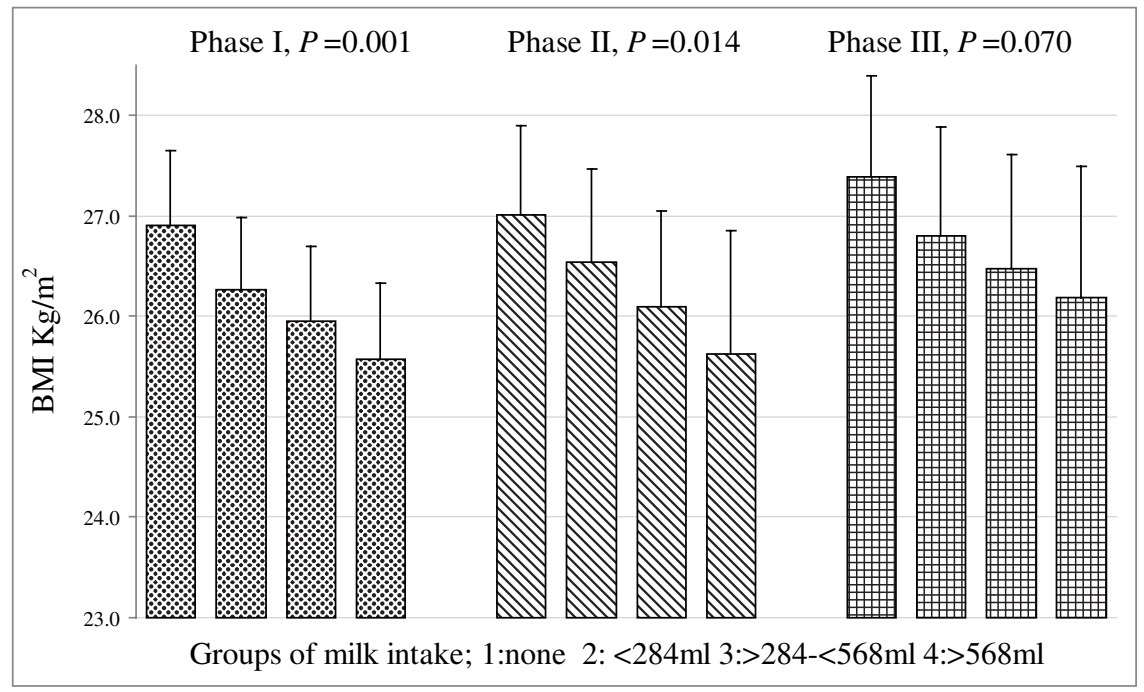

In the multivariate regression analysis with adjustment for potential confounding effects there were trends toward inverse associations between dairy consumption and body weight across all phases $(P<0.1)$. When butter was excluded dairy consumption was inversely associated with body weight across phases I-III $(P=0.001, P=0.054$ and $P=0.052$ respectively $)$ and men in the highest intake quartile had 4.2, 4.6 and $4.0 \%$ lower sum of skinfolds $(P=0.001)$, central (sum of abdominal and subscapular skinfolds; $P=0.001)$ and peripheral obesity (sum of biceps and triceps skinfolds; $P=0.047$ ) respectively compared with men in the lowest quartile. Examination of the individual dairy products showed that milk was the only food independently inversely related to total body weight and adiposity across all phases (Figure). Variables that were lower in the group who consumed $>568 \mathrm{ml} / \mathrm{d}$ compared with no milk drinkers were BMI $\left(1.3 \mathrm{~kg} / \mathrm{m}^{2}\right.$; $P<0.05)$, sum of skinfolds $(10.3 \% ; P=0.003)$, central obesity $(10.6 \% ; P=0.001)$ and peripheral obesity $(8.3 \% ; P=0.057)$.

These findings are in agreement with the suggested favourable effects of dairy consumption on body fatness but provide new evidence that most of the effect is associated with drinking milk. Results also highlight that milk consumption could be used as part of a dietary strategy for body-weight control in middle-aged men.

1. Major GC, Chaput JP, Ledoux M et al. (2008) Obes Rev 09, 428-445.

2. Elwood PC, Pickering JE \& Fehily AM (2007) J Epidemiol Community Health 61, 695-698. 